\title{
Development and Evaluation of a Low-Density Biomass Feeding System for Fluidized Bed Gasifiers
}

\author{
${ }^{1}$ A.E. Ghaly, ${ }^{2}$ A. Ergudenler, ${ }^{3}$ S. Alsuhaibani, ${ }^{1}$ V. V. Ramakrishnan \\ ${ }^{1}$ Process Engineering and Applied Science Department, \\ Faculty of Engineering, Dalhousie University, Halifax, Nova Scotia, Canada; \\ ${ }^{2}$ Air Quality and Management Division, Policing and Planning Department, \\ Greater Vancouver Regional District, Burnaby, British Columbia, Canada; \\ ${ }^{3}$ Agricultural Engineering Department, College of Agriculture and Food Sciences, \\ King Saud University, Riyadh, Kingdom of Saudi Arabia.
}

Received 2013-10-02; Revised 2013-11-06; Accepted 2013-11-07

\begin{abstract}
For efficient operation of a biomass gasifier, the biomass material must be fed continuously to the system. A feeding system for chopped straw and rice husk was designed, constructed and evaluated. It consisted of: A frame, a hopper, an auger, two agitators, a drive system and a power unit. Initial testing showed that wheat straw and rice husk, being highly cohesive materials, created tunnel flow and piping conditions. This occurs when the pressure above an impending dome of material is too small resulting in the creation of a stable dome and blockage of the discharge. In order to achieve good flow conditions, it was concluded that the hopper must operate under "mass outflow" and the material should not be allowed to build up along the flow channels. These objectives were achieved by the proper redesign of the hopper configuration, the installation of agitators in the hopper and use of an auger in the outlet duct leading into the gasifier. However, as the augur was used to move the biomass material from hopper to the gasifier, it was observed that hot gases leaked from the gasifier into the hopper and heat was also transmitted from the gasifier to the hopper though the augur shaft by conduction resulting in burning of biomass material in the hopper. Therefore, the augur shaft was fitted with copper tubing to serve as a water cooling system and the tapered section of the augur was fitted with a stainless steel section with water inlet and outlet to serve as a secondary cooling system. After, the system has been successfully modified for feeding wheat straw and rice husk, it was tested to determine the optimum operating conditions. Mass flow tests were performed with four sprocket combinations and four auger speeds. Increasing the auger speed and/or the lower agitator speed increased the straw output of the feeding system. However, increases in the upper agitator speed resulted in reduced mass flow of the material due to the mixing effect created by the upper agitator which reduced the down movement of the straw toward the auger housing. The sprocket B combination (30 tooth sprocket on the lower agitator shaft and a 50 tooth sprocket on the upper agitator shaft with a lower agitator speed of $1 / 3$ auger speed and an upper agitator speed of $1 / 15$ auger speed) gave the greatest straw output. The feed rate at this combination ranged from 0.74 to $6.76 \mathrm{~kg} /$ minute (12.58 to $114.92 \mathrm{GJ} / \mathrm{minute})$. By adjusting the dial controller, the output could be easily matched with the gasifier's required straw input.
\end{abstract}

Keywords: Rice husk, wheat straw, chopping, hopper, augur, agitators, drive system, water cooling system, sprockets, straw output

\section{INTRODUCTION}

Currently, most of the energy requirements of the world are met by fossil fuels. The fossils fuels are mixtures of hydrocarbons containing various amounts of carbon and nitrogen. The deposits of fossil fuels are being depleted in a rapid pace and the uncertainty and the safety of their supplies are of major concern. Furthermore, their combustion result in various gases (carbon-di-oxide, carbon-mono-oxide, methane,

Corresponding Author: Ghaly, A.E., Department of Process Engineering and Applied Science, Dalhousie University, Halifax, Nova Scotia, Canada B3J 2×4, Canada. Email: abdel.ghaly@dal.ca 
nitrous oxide and sulfur oxide) which cause global warming, acid rain and destruction of ozone layer, thereby affecting the earth's climatic conditions, human health and agricultural product system (Olah, 2005; Shafiee and Topal, 2009). IEA (2012) reported that $81.2 \%$ world's energy supply is met by fossil fuels (coal/peat contribution is $20 \%$, oil contribution is $36.3 \%$ and natural gas contribution is $24.9 \%$ ). The other $19.8 \%$ of the energy supply is met by alternative source of energy (nuclear contribution is $10.2 \%$, hydro contribution is $2.3 \%$, biofuels from waste contribution is $4.9 \%$ and geothermal, solar and wind contribution is $1.4 \%)$.

To satisfy world's energy needs, other sources must be developed. Renewable bioenergy sources such as agricultural plant residues (cereal straws, rice husks, corn stalks, sawdust and peat), animal wastes and forest residues can provide a continuous supply of liquid and gaseous biofuels (Saxena et al., 2009). Although, these biomass sources are widely considered as major potential resources for future energy generation (Chum and Overend, 2001; Sims et al., 2003; Demirbas, 2005), they are mostly solid materials that are difficult to use (as produced) in many applications without substantial modification and proper feeding systems (Bridgewater, 1995). The most abundant biomass material with potential as a bioenergy sources are cereal straws and rice husks.

Straws are plant residues of grain crops such as wheat, rice, barley, rye and oats. The amount of straw produced varies depending on climatic and soil conditions. The straw/grain ratio has been used to calculate the amount of straw produced from various crops as shown in Table 1. The total production of straw in Canada is over 82.4 million tonnes per year (Li et al., 2012). Wheat straw dominates the total straw production and $92.6 \%$ of it is produced in Canadian Prairies. Most corn straw (96.7\%) and soybean straw (95.4\%) are produced in Ontario and Quebec, respectively. A significant part of the straw $(60-80 \%)$ can be made available for energy recovery through combustion and gasification processes to meet demands for space and water heating, grain drying and for operating small stationary machined on Canadian farms (Chum and Overend, 2001; Demirbas, 2001; Demirbas, 2005; Li et al., 2012).

Rice husks are generated in large quantities as a major by-product in the rice milling industry.
Table 1. Straw/grain ratio for Canadian Crops (Li et al., 2012)

\begin{tabular}{lcc}
\hline Crop & Straw/grain Ratio & $\begin{array}{c}\text { Straw } \\
(\%)\end{array}$ \\
\hline Spring Wheat & 1.6 & 62 \\
Winter Wheat & 1.2 & 55 \\
Durum Wheat & 1.66 & 62 \\
Barley & 1 & 50 \\
Canola & 1 & 50 \\
Oats & 1.5 & 60 \\
Dry Peas & 1 & 50 \\
Flax & 1.2 & 55 \\
Corn for grain & 1 & 50 \\
Soybean & 1 & 50 \\
Tame Hay & 0 & 100 \\
Fodder Corn & 0 & 100 \\
\hline
\end{tabular}

Around $20-22 \%$ of weight of the rice paddy consists of husk (Pushpakumara and De Silve, 2012). In 2012, the worldwide production of rice was 728.7 million tones. The estimated worldwide husk production is about 145.74 million tons, of which about $90 \%$ is generated in developing countries (FAO, 2013). Disposal of these vast amounts of rice husk has been one of the major problems facing the rice milling industry. Because rice husk is a renewable source of energy, it can be used in thermochemical conversion technologies such as pyrolysis, combustion and gasification systems as a potential source of biofuel (Beagle, 1978; Ebeling and Jenkins, 1985; and Mansaray and Ghaly, 1997).

Because of a wider range of applications of the gasification products, a concerted effort has been made to develop reactors suitable for gasification of biomass. However, gasification systems, designed to utilize biomass materials such wheat straw and rice husk, require a continuous flow of the fuel material at a constant rate. The main objective of this study was to design, construct and evaluate a feeding system of low density biomass materials for use with fluidized bed gasification systems.

\section{THE FLUDIZED BED GASIFICATION SYSTEM}

Figure 1 shows a schematic of the fluidized bed gasification system used in this study. It is a further development of a spout-fluidized bed in which a bubbling fluidized bed is maintained towards the outer region of the bed while the active spout is maintained at the center. The basic physical difference between the two, is the presence of a secondary distributor plate in the spout (above secondary column). 


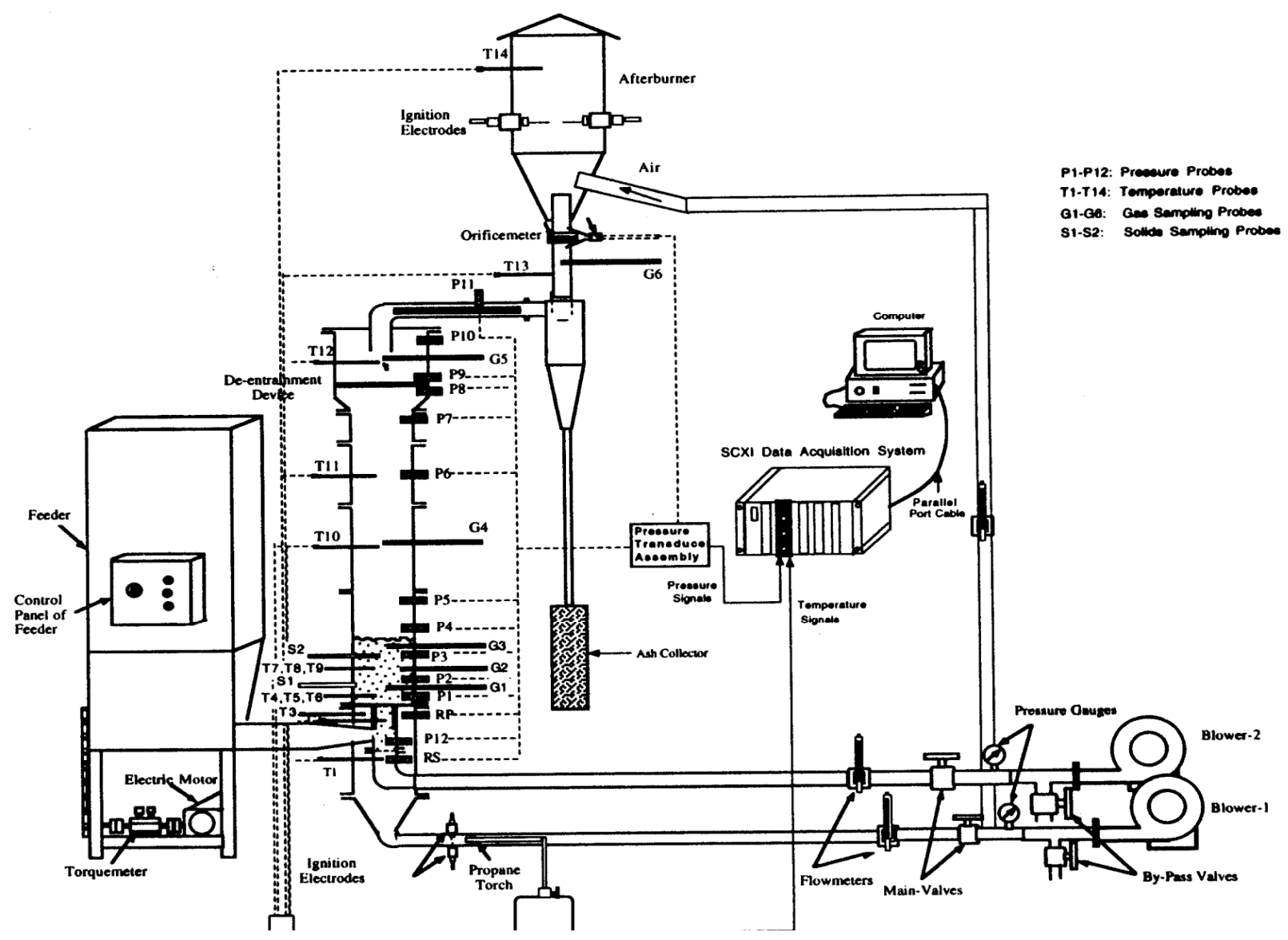

Fig 1. Fluidized bed gasification system.

By virtue of its design, the dual distributor fluidized bed ensures a more homogeneous mixture of biomass bed materials since the biomass is pneumatically introduced through the bottom center of the reactor by the secondary column. The uniform biomass distribution in the dual distributor fluidized bed is assured by the spout which entrains bed particles from the bottom of the bed, mixing them with biomass and secondary air and then transporting the mixture in the upper region of the bed. From here, bed particles and the unreacted biomass proceed in a three dimensional fashion; their direction is determined by the movement of bubbles in the bed. The systematic pattern of solids movement gives rise to a unique hydrodynamic system which is more suitable for the gasification of low density biomass materials compared to other conventional fluid-solid configurations.
The fluidized unreacted biomass proceed in a three dimensional fashion; their direction is determined by the bed gasifier was made of $8 \mathrm{~mm}$ thick, 310 stainless steelcylinder of $255 \mathrm{~mm}$ diameter and $2700 \mathrm{~mm}$ total height. The primary air (for fluidization), secondary air (for feeding) and the air required for the after burner are supplied to the fluidized bed reactor by two identical air supply units. Each unit consisted of a blower, a pressure gauge having a pressure range of $0-690 \mathrm{kPa}$, a main valve to control the air flow rate, a by-pass valve to prevent overheating of the electric motor, a steel pipe having an inner diameter of $50 \mathrm{~mm}$ and a flowmeter. The blower (Model ENGENAIR R4310A-2, Benton Harbour, Michigan) is driven by a $4.8 \mathrm{hp}$ (three-phase 220 volts and 13.4 amps) electric motor (Baldor Industrial Motor, Benton Harbour, Michigan) and had a maximum flow capacity of $4.87 \mathrm{~m}^{3} / \mathrm{min}$ and maximum pressure of $20 \mathrm{kPa}$. Each 
blower inlet had a filter with a micron rating of 25 and a maximum flow of $7.08 \mathrm{~m}^{3} / \mathrm{min}$ to clean the incoming air of contaminants such as dust particles and water. Flow Cell Bypass flowmeters (Metal FLT-type, Cole Parrnar Catalog No. N-03251-60, Chicago, Illinois) were used to measure the air supply rates. Each flowmeter was accurate to $2.5 \%$ of full scale and could be used up to maximum temperature and pressure of $60^{\circ} \mathrm{C}$ and $1035 \mathrm{kPa}$, respectively.

An enlarged disengagement section mounted on the top of the main fluidizing column was used to reduce the elutriation rate from the fluidized bed. The height of the enlarged section was $395 \mathrm{~mm}$ whereas the bottom and top diameters were $255 \mathrm{~mm}$ and 355, respectively. The angle of inclination was 300 from the vertical axis. A cyclone was connected to the exit of the disengagement section to capture the solid particles (dust, ash and char) escaping from the bed. The fluidizing column and cyclone were insulated using a flexible blanket (Inswool-HP Blanket, A.P. Green Industries Inc., New Mexico, Missouri) to reduce heat loss from the system. The gas leaves the cyclone through a stainless steel pipe of $150 \mathrm{~mm}$ inside diameter to the combustion chamber of an afterburner.

\section{DEVELOPMENT OF THE FEEDING SYSTEM}

The feeding system (Figure 2) was designed for feeding low density biomass materials into a fluidized bed gasification system. It consists of: (a) a frame, which is used to raise the hopper above the auger, support the auger and agitators and provide a rigid mounting for the power system, (b) a hopper, which serves as a holding container and chute for the biomass material, (c) two agitators, which are made from steel rods with wire spikes extending from them to loosen and mix the biomass material, (d) an auger, which is a simple screw used for moving the biomass material from the hopper to the gasifier, (e) a reducer assembly, which is used to first compact the biomass material at the end of the auger housing to avoid backflow of hot gases into the hopper and then to loosen it at the end of the assembly in order to be carried pneumatically to the gasifier by the secondary air supply through the secondary column, and (f) a drive system, which consists of an electric motor, a speed controller and various chains and sprockets.

\subsection{The Frame}

The frame (Figure 3) is a structural arrangement of angle iron used to position the hopper over the auger and to support and align the auger and agitators.

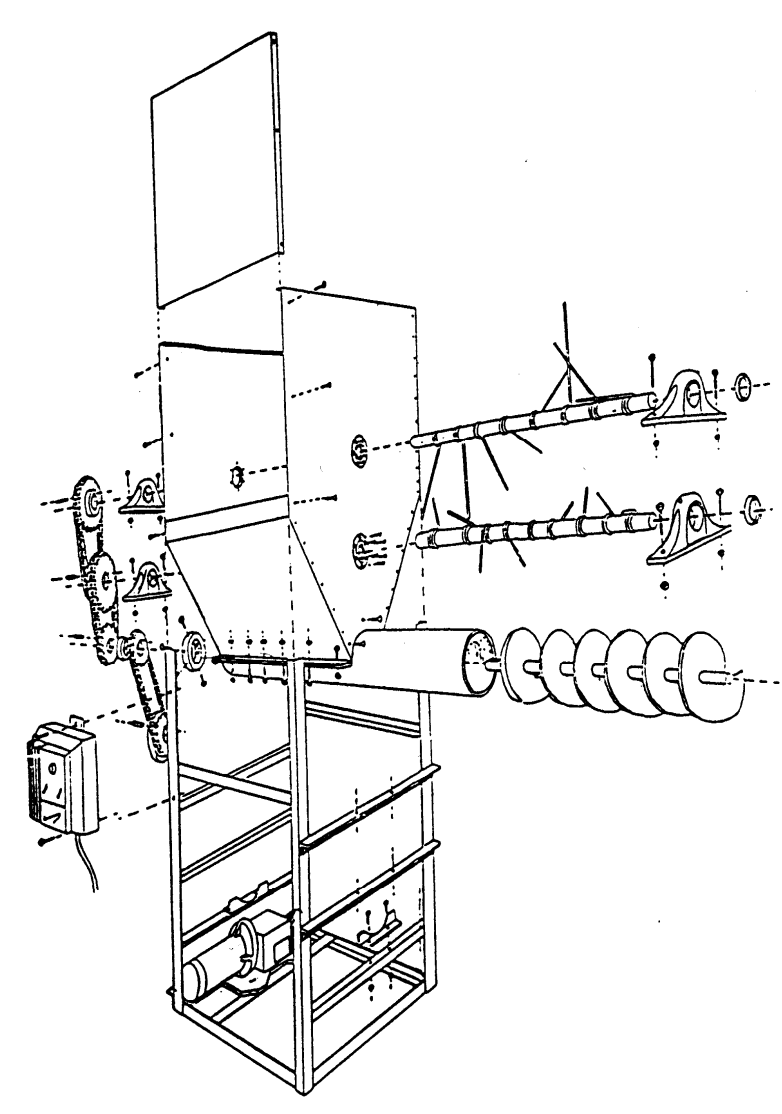

Fig 2. The biomass feeding system.

The frame was designed in such a way that the hopper assembly can slide in and out for easy evaluation and modification. The main frame was made of $50 \mathrm{~mm}$ mild steel angle iron. The supports for the agitators and auger were made of $41 \mathrm{~mm}$ mild steel angle iron. The base of the frame was $610 \mathrm{~mm}$ X $500 \mathrm{~mm}$ and the height was $1210 \mathrm{~mm}$. The angle iron of the main frame section, which forms the rectangular housing portion of the hopper, were single fillet arc-welded together. The cross sectional pieces were bolted onto the main frame using two $12.7 \mathrm{~mm}$ X $25.4 \mathrm{~mm} \mathrm{UNC} \mathrm{bolts} \mathrm{and} \mathrm{hex} \mathrm{nuts}$ on each end. The supports of the auger, lower agitator and upper agitator were located on the front and back of the frame at heights of 325, 505, and $675 \mathrm{~mm}$, respectively. Additional frame reinforcements were made of $41 \mathrm{~mm}$ mild steel angle iron arc-welded with single fillets and located on the sides of the frame at a height of $750 \mathrm{~mm}$. 


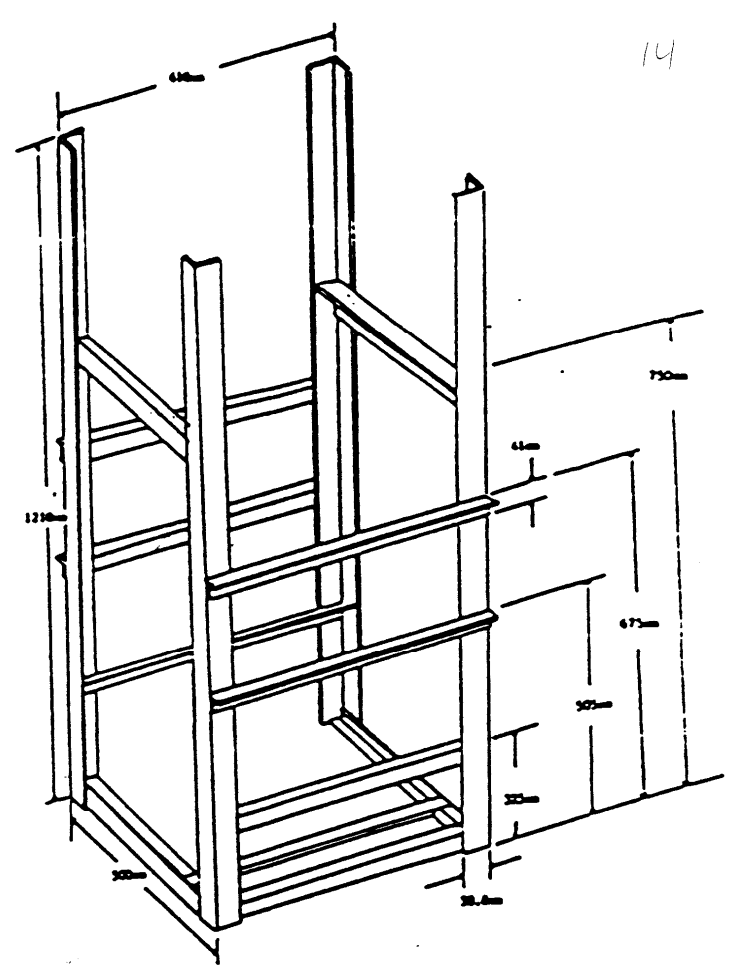

Fig 3. The supporting frame of the biomass feeding system.

\subsection{The Hopper}

The hopper (Figure 4) is a funnel shaped reservoir from which the biomass material is discharged into an auger located at its base. It was made of 6 pieces of 18 gauge galvanized sheet metal. The upper section of the hopper resembles a cube having dimensions of $500 \mathrm{~mm}$, $490 \mathrm{~mm}$, and $590 \mathrm{~mm}$ for the depth, length and width, respectively. Three of the sides were pop riveted together using sixteen $10 \mathrm{~mm}$ pop rivets, spaced $75 \mathrm{~mm}$ apart. The fourth side (removable section) was held in place with 6 machine screws, 3 placed equidistant on each end. The lower section of the hopper resembles a prism having dimensions at the bottom end of 505, 490 and $590 \mathrm{~mm}$ for the depth, length and width, respectively. The angle of inclination of the lower section of the hopper was $28^{\circ}$ to vertical. Where the lower section of the hopper connects with the auger housing, the sheet metal was flared out to form a flange where eight $12 \mathrm{~mm}$ holes were spaced evenly on each flange. To connect the auger casing to the front and back of the hopper, 3 evenly spaced $7 \mathrm{~mm}$ x $25 \mathrm{~mm}$ cap screws and hex nuts were used at each end.

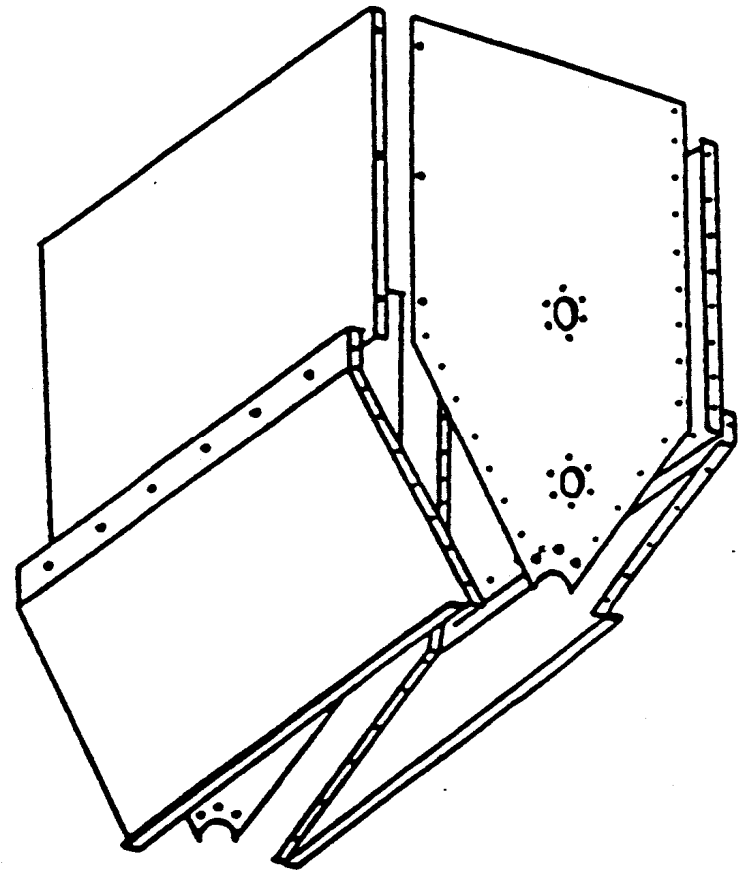

Fig 4. The hopper.

Seal supports were placed where the agitators enter and exit the hopper to seal the circular opening. These were held in place with six $7 \mathrm{~mm} \times 25 \mathrm{~mm}$ cap screws and hex nuts.

\subsection{The Agitators}

The agitators were found necessary to prevent the biomass materials from settling and consolidating to form a bridge. They were used to loosen mix the material to keep the fuel supply homogeneous and consistent. Two agitators were made of $25 \mathrm{~mm}$ diameter steel shafts (Figure 5) with wire wrapped around them 4 turns and extended to form spikes. There were small holes drilled in each end of the shaft for the wrapped ends of the wires in order to prevent them from rotating around the shaft. As the force of resistance of the biomass material tries to wrap the wires around the shaft, the wires tighten themselves onto the shaft. The upper agitator had 8 music gauge wires extending $170 \mathrm{~mm}$ radially whereas the lower agitator had 9 music gauge wires extending 80 $\mathrm{mm}$. radially. To support the shafts at each end, nonexpansion 2-bolt pillow blocks (lubricated with grease) were utilized. These pillow blocks were bolted onto horizontal angle iron supports using two $14 \mathrm{~mm}$ x $50 \mathrm{~mm}$ UNC bolts and hex nuts each. 


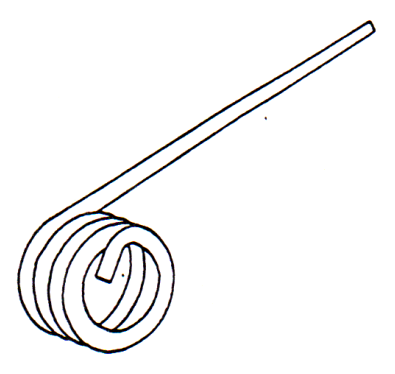

(a) Wire Spike

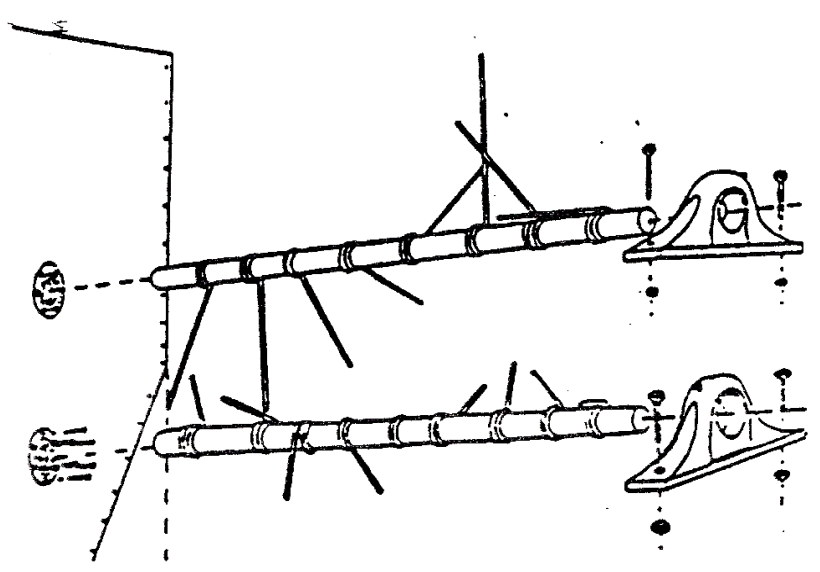

(b) Agitators shaft with spikes

Fig 5. The agitators.

\subsection{The Augur}

The auger system (Figure 6) consists of the auger screw and housing. The section under the hopper was split length-wise horizontally with 4 steel flanges arc welded onto the cylinder for connection with the hopper. The auger shaft was placed horizontally in the auger sleeve, $7.6 \mathrm{~cm}$ above the bottom of the base of the feed tank, and was driven via a gear and chain by a variable speed motor (Leeson Company Model No. N182-D17FK- 2A, Grafton, Wisconsin, USA). The augur was a $1000 \mathrm{~mm}$ long single thread right hand design. The auger screw was made of $8 \mathrm{~mm}$ thick stainless steel tightening tig welded to a $1200 \mathrm{~mm}$ long 316 stainless steel shaft of $30 \mathrm{~mm}$ outer diameter and $10 \mathrm{~mm}$ inner diameter. The pitch of the flighting was $150 \mathrm{~mm}$. A copper tubing of 6 $\mathrm{mm}$ in diameter was fitted inside the steel cylinder and served as a water cooling system. This was necessary since one end of the auger housing was exposed to high the temperature generated in the secondary column of the fluidized bed gasifier.

The housing for the auger was made of stainless steel cylinder of $10 \mathrm{~mm}$ thick wall and $95 \mathrm{~mm}$ in diameter. The tapered section was located $250 \mathrm{~mm}$ apart from the hopper exit and followed by a straight section in which the pitch size of the auger flights was increased in order to break down the compacted biomass material into a loose form in order to avoid jamming of biomass in the secondary column. The reducer assembly was made of $1.6 \mathrm{~mm}$ thick stainless steel, straight section of $100 \mathrm{~mm}$ in length and of $104 \mathrm{~mm}$ in diameter which was tig welded to a tapered section of $280 \mathrm{~mm}$ in length and 60 $\mathrm{mm}$ in diameter. A section of stainless steel stock of 1.6 $\mathrm{mm}$ thick and $162 \mathrm{~mm}$ in length was welded around the tapered section to serve as a water-cooled zone. A stainless steel flange of $6 \mathrm{~mm}$ thickness and $152 \mathrm{~mm}$ outer diameter $(60 \mathrm{~mm}$ id) with drilled holes of $9 \mathrm{~mm}$ in diameter was welded onto output end of the driver assembly. A second stainless steel flange of $6 \mathrm{~mm}$ thickness and $152 \mathrm{~mm}$ outer diameter $(60 \mathrm{~mm}$ id) with drilled holes of $9 \mathrm{~mm}$ in diameter was welded onto the input end of each end of the reducer. The driven end of the auger, which rotates in a double row angular contact thrust bearing, was connected to the auger housing by four $12 \mathrm{~mm}$ x $25 \mathrm{~mm} \mathrm{UNC}$ bolts and hex nuts to prevent the auger from sliding out of alignment. The output end of the auger rotates freely inside the auger housing. The auger rotates with a clearance of $5 \mathrm{~mm}$ and $0.001 \mathrm{~mm}$ on the top and bottom, respectively.

\subsection{The Pneumatic Feeding System}

Effective pneumatic feeding of low density fuel material was achieved by adapting a dual- distributor type feeding system to the fluidized bed gasifier (Figure 7). The system consisted of the main distributor plate which carried the sand, the secondary column through which the material gas carried with a jet of air into the gasification column where it was mixed with the hot bed material, the secondary distributor plate which prevented the bed material from entering the air supply system and the feeding tube which transported the biomass fuel from the auger casing into the secondary column. The system allowed direct feeding of the biomass fuel from the bottom through the center of the main distributor plate. A combination of various elbows of varying dimensions in the reduced assembly was instigated in relation to biomass compaction at the end of the auger housing. 


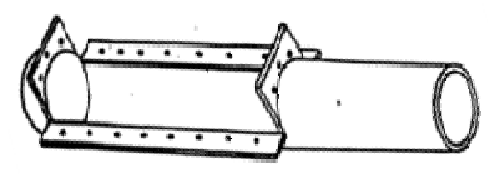

(a) The housing section under the hopper

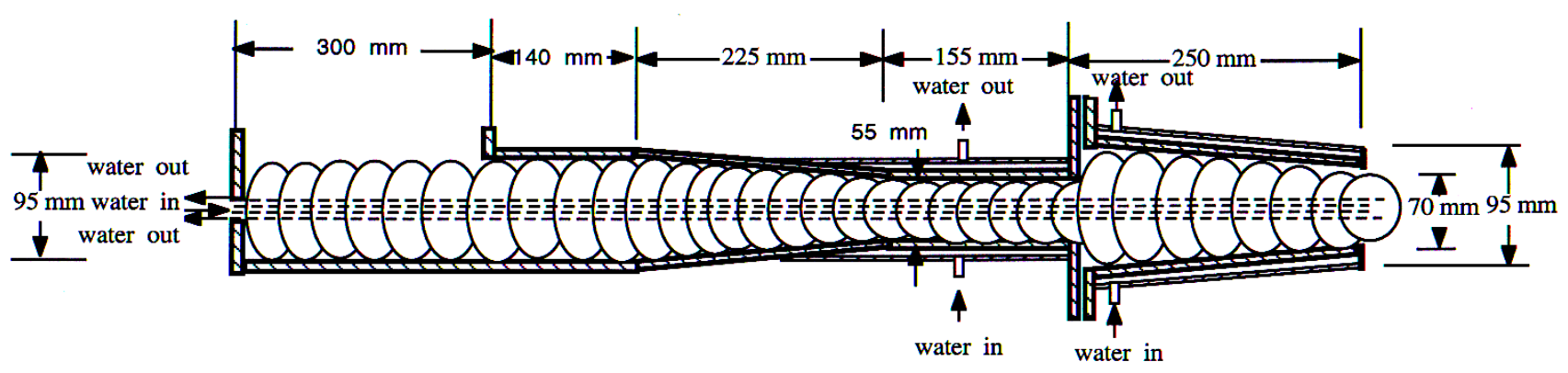

(b) The various section of augur in housing

Fig 6. Augur feeding system.

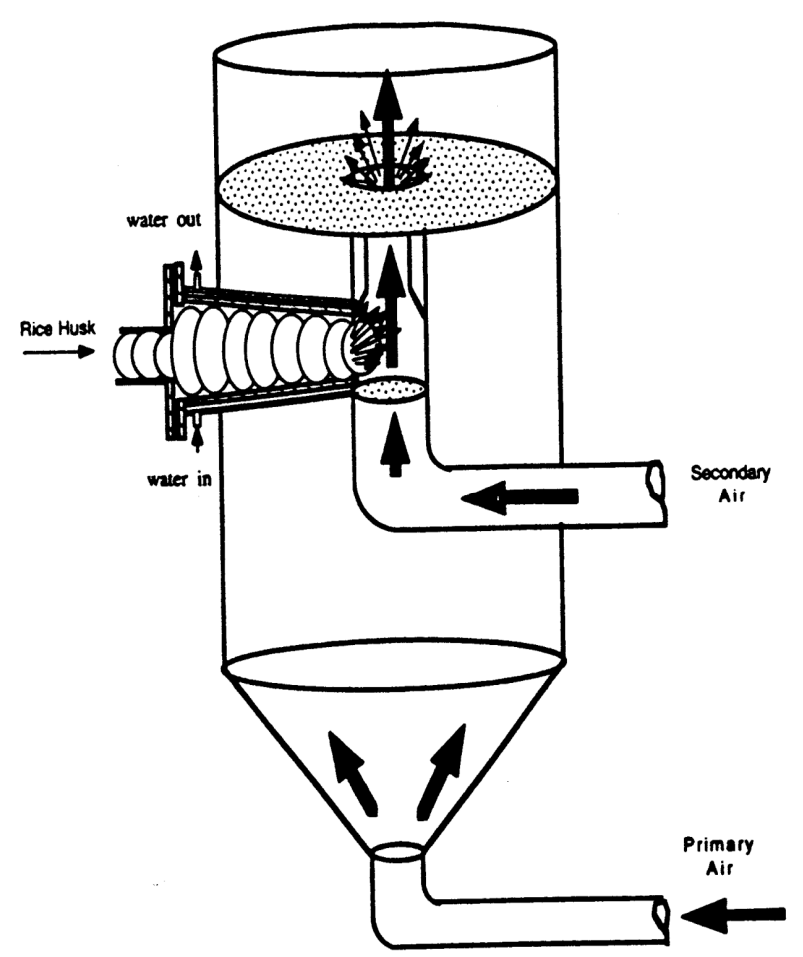

Fig 7. Pneumatic feeding system.
The aim was to arrive at a proper design of a reducing section that would provide compaction enough to stop the flow of hot gases from the gasifier into the feeding system and of a reducing elbow that would provide maximum flowability of biomass in the secondary column. The final design consists of a 90 reducing elbow of $95 \mathrm{~mm}$ diameter at the horizontal end (auger end) and $78 \mathrm{~mm}$ diameter at the vertical end (distributor plate end). The auger end was connected to the auger housing by four $12 \mathrm{~mm}$ x $50 \mathrm{~mm} \mathrm{UNC} \mathrm{bolts} \mathrm{and} \mathrm{hex} \mathrm{nuts} \mathrm{through}$ square flanges of $157 \mathrm{~mm} \times 157 \mathrm{~mm}$. The certical end was tig welded to the distributor plate. The main and secondary distribution plates are shown in Figure 8.

\subsection{The Drive System}

The drive system (Figure 9) consists of a motor, a speed controller and various chains and sprockets. The motor, used to drive the agitators and the auger is a continuous duty, 3/4 hp motor (Honeywell Field Model No. SR 3736-3 162, Pacific Scientific,Chandler, Arizona, USA). It was mounted on the base of the frame, solidly, with four $2 \mathrm{~mm}$ x $25 \mathrm{~mm}$ UNC bolts and hex nuts. The motor speed was controlled by a speed controller (Browning Model LWS 25/200, Sidney, Ohio, USA) connected in series between the 115 volt power source and the motor. 


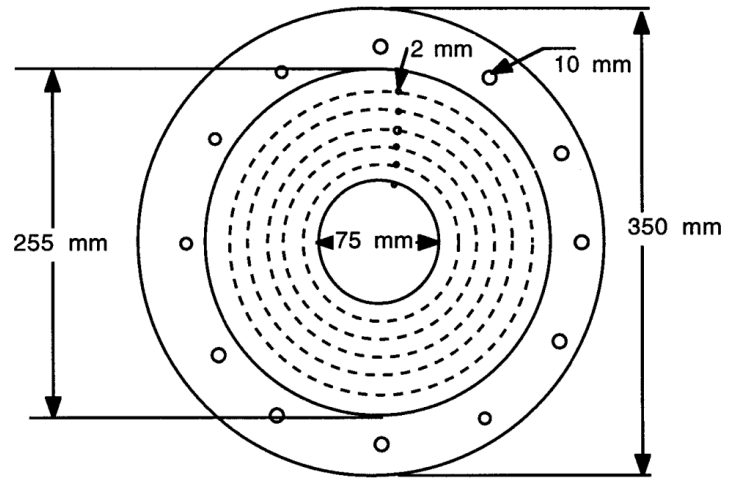

(a) Main

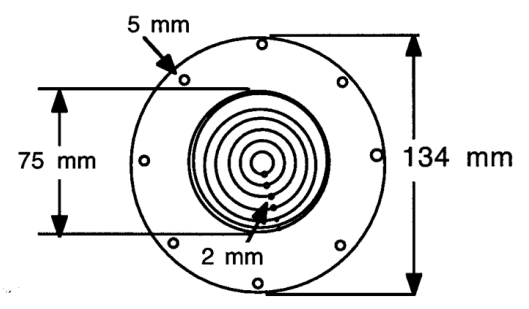

(b) Secondary

Fig 8. Main and secondary distributor plates.

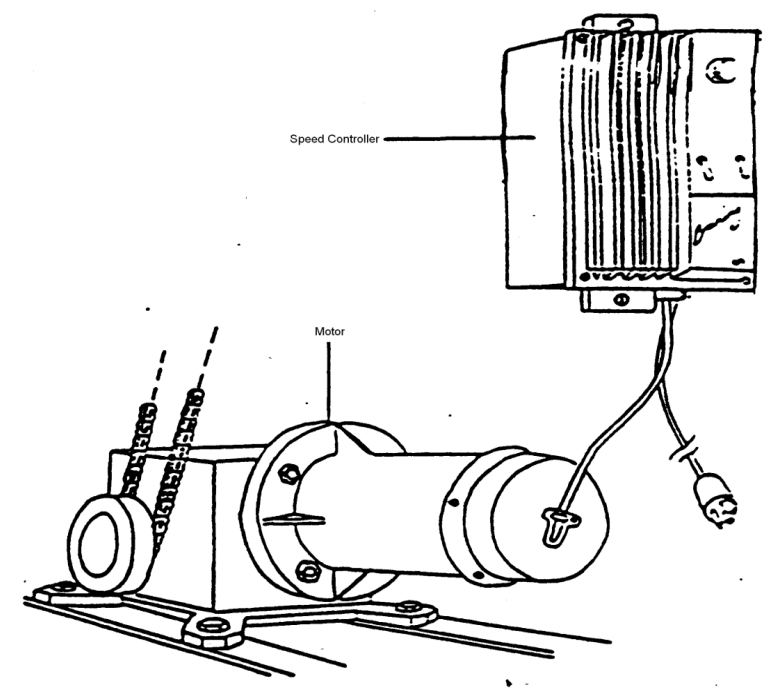

Fig 9. The drive system.

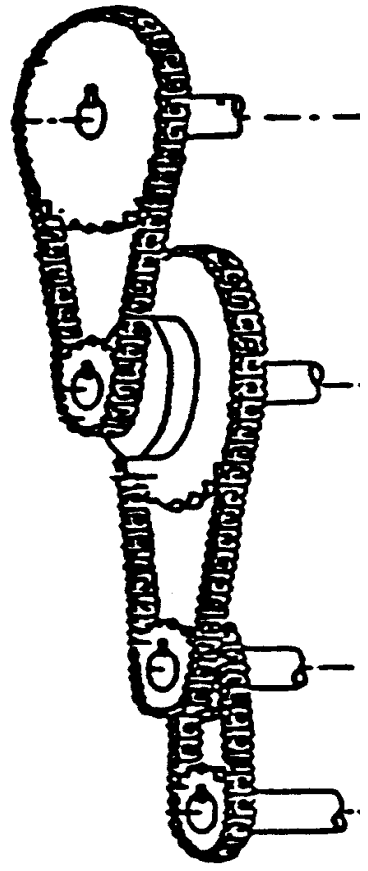

Fig 10. The sprocket system.

This controller allowed the angular speed of the auger to be varied in increments from $0 \mathrm{rpm}$ to $60 \mathrm{rpm}$. The sprockets and roller chains, which connect the motor with the auger and agitators, were number 40 (13 nim pitch). The sprockets are made of steel with hardened teeth and run with a light lubricant from the chain. The sprockets are prevented from rotating on the shafts using keys made of $5 \mathrm{~mm}$ x $5 \mathrm{~mm}$ keystock and keyways. The sprockets were arranged so as to give a 1:1 speed ratio from the motor to the auger, a 5:1 speed ratio from the auger to the lower agitator, and a 3:1 speed ratio from the lower agitator to the upper agitator as shown in Figure 10.

\section{BIOMASS COLLECTION AND ANALYSES}

\subsection{Biomass Collection}

Monopol variety winter wheat straw was used in chopped form (average size of 2-15 mm). The wheat straw was initially collected in the form of small bales $(0.46 \mathrm{~m} \times 0.48 \mathrm{~m} \times 0.70 \mathrm{~m})$ from a field on the Dyke View Farms situated at site at Port Williams, Nova Scotia. To maintain a uniform straw composition, straw was collected during the same harvesting season and 
from the same field. The straw bales were placed in a drying system and dried by blowing warm air $\left(35^{\circ} \mathrm{C}\right)$ before they were chopped, in order to obtain a consistent moisture content of the feedstock. The rice husk (lemont variety), was obtained from Brousand Ricemifis, Louisiana, United States of America. The rice husk was relatively uniform and did not require any treatment before use. Some characteristics of the wheat rice husk are given in Table 2.

\subsection{Moisture Content}

Moisture content tests were performed on the asreceived biomass samples (wheat straw, rice husk, peat and diesel contaminated peat) by oven drying method, according to the ASTM D 3173-73 procedure. Samples weighing approximately $5 \mathrm{~g}$ each were placed in large aluminum dishes. The dishes containing the biomass were placed in an air forced drying oven (Isotemp Oven Model No. 655F, Fisher Scientific, Toronto, Ontario) at $105^{\circ} \mathrm{C}$ for at least 24 hours. The moisture content of the biomass was then calculated on wet basis as follows:

$$
\mathrm{MC}_{\mathrm{wet}} \frac{(\mathrm{WW}-\mathrm{DW})}{\mathrm{WW}} \mathrm{X} 100
$$

Where:

$\mathrm{MC}$ is the moisture content on wet basis (\%)

WW is the wet weight of the sample $(\mathrm{kg})$

DW is the dry weight of the sample $(\mathrm{kg})$

\subsection{Bulk Density}

The bulk densities of the biomass samples were determined according to the ASTM Standard Method for the Bulk Density of Particulate Biomass Fuels, E 873-82. A cylindrical container $(6 \mathrm{~cm}$ in diameter and $6.2 \mathrm{~cm}$ high, inside dimensions) was used. The empty container was weighed using a Mettler Balance (Model No. PM 4600, Mettler Instrumente AG, Greifensee, Zurich) with an accuracy of $\pm 10 \mathrm{~g}$. The container was filled by pouring loose biomass from the top edge of the container. The container and sample were then weighed and the net mass of the material was divided by the volume of the container to obtain the bulk density as follows:

$$
\rho_{\mathrm{b}}=\frac{(\mathrm{F}-\mathrm{E})}{\mathrm{V}}
$$

Table 2. Some characteristics of biomass materials.

\begin{tabular}{lcc}
\hline Characteristics & Straw & Rice Husk \\
\hline Moisture Content $(\%)$ & 10.11 & 9.08 \\
Particle size $(\mathrm{mm})$ & $2.0-15.0$ & $0.8-12.4$ \\
Bulk Density $\left(\mathrm{kg} / \mathrm{m}^{3}\right)$ & 75.80 & 92.00 \\
Lower Heating Value (MJ/Kg) & $18 . .71$ & 14.22 \\
Proximate Analysis*(\%) & & \\
Volatile Matter & 78.80 & 66.40 \\
Fixed Carbon & 17.61 & 13.60 \\
Ash & 3.59 & 20.00 \\
C & & \\
H & 45.97 & 37.60 \\
O & 5.78 & 5.42 \\
N & 44.15 & 36.56 \\
S & 0.55 & 0.38 \\
Cl & 0.12 & 0.03 \\
Ash & 0.02 & 0.01 \\
& 3.41 & 20.00 \\
\hline
\end{tabular}

*Weight percentage on dry basis

Where:

$$
\begin{aligned}
& \mathrm{Pb} \text { is the bulk density of the sample }\left(\mathrm{kg} / \mathrm{m}^{3}\right) \\
& \mathrm{F} \text { is the weight of container and sample }(\mathrm{kg}) \\
& \mathrm{E} \text { is the weight of container }(\mathrm{kg}) \\
& \mathrm{V} \text { is the volume of container }\left(\mathrm{m}^{3}\right)
\end{aligned}
$$

\subsection{Particle Size Distribution}

Samples from the biomass materials were selected randomly for sieve analysis to determine the size distribution of biomass particles. The size distribution was determined using eight standard sieves (Canadian Standard Sieve Series, W.S. Tyler Company of Canada Limited, St. Catharines, Ontario) and a bottom pan, the latter collects everything that passes through the eighth sieve. The sieves were mounted on an electrical sieve shaker (Model Rx-86, Hoskin Scientific Limited., Gastonia, North Carolina, USA) driven by a $0.25-\mathrm{hp}$ electric motor running at $1,725 \mathrm{rpm}$. The shaker was running at a speed of $350 \mathrm{rpm}$. About $1.0 \mathrm{~kg}$ of a given biomass material was put into sieve no. 1, which was then covered with the sieve lid. The shaker was operated for 30 minutes. The biomass particles collected in each sieve were analyzed for weight, width and length distribution.

\section{EVALUATION OF THE FEEDING SYSTEM}

\subsection{Experimental Design}

The motor speed controller has a dial reading with ten speed settings. Those appear as numbers (1-10) on 
the dial scale. To achieve a good cross-sectional representation of the straw feeder flow rate range, four different speed settings were chosen: one, four, seven and ten $(7,24,42$ and $54 \mathrm{rpm}$, respectively). To study the effect of various agitation speeds on the straw output, the upper and lower agitator drive sprockets were changed. A combination of two number 40 sprockets having 30 and 50 teeth were used. This provided four combinations and a range of speed ratio (auger to agitator) of 1/3-1/5 for the lower agitator and 1/9-1/25 for the upper agitator as shown in Table 3. The agitators speeds in relation to the auger speed are shown in Table 4.

A minimum of five 4 ply plastic bags ( $400 \mathrm{~mm} \times 600$ $\mathrm{mm})$ were filled with straw during each experimental run. The choice of five bags per replicate was based on the principle that the hopper will not be repeatedly filled and embtied during the actual feeding of the gasification system but rather maintained at $75 \%$ capacity by the continuous feeding of the chopped straw from the straw chopper. Thus, by using five bags, the effect of the weight of straw in the hopper on the settling and consolidation of straw was nulified. The testing procedure included 48 experimental runs which provided 240 measurements.

\subsection{Testing Protocol}

For a given experimental run (auger/agitators speed combinations), the hopper was first filled with biomass material up to a $50 \mathrm{~mm}$ mark below the top of the hopper. The indicator dial on the speed controller was placed on the desired speed setting. The motor was then turned on and the auger speed was fine tuned to the desired RPM (measured using a hand tachometer) by adjusting the dial controller. A small amount of biomass discharged out of the auger tube while adjusting the speed. The motor was then turned off.

The first bag was placed over the open end of auger and the motor and stopwatch were turned on simultaneously. When the time allocated for the first bag was over, the first bag was removed and the second bag was placed over the opening. This was done carefully to avoid spilling of material. The bag changing procedure was repeated until the fifth bag was filled. The motor was then turned off and the bags were weighed.

The hopper was refilled to the same mark. The speed setting was then changed to the next lowest test setting and the above procedure was repeated.
Table 3. Agitators sprockets combinations and speeds.

\begin{tabular}{lccccc}
\hline Combinations & \multicolumn{2}{c}{$\begin{array}{c}\text { Sprocket's Number } \\
\text { of Teeth* }\end{array}$} & & \multicolumn{2}{c}{$\begin{array}{c}\text { Agitator's } \\
\text { Speed** }\end{array}$} \\
\cline { 2 - 3 } \cline { 5 - 6 } & Lower & Upper & & Lower & Upper \\
\hline $\mathrm{A}$ & 30 & 30 & & $1 / 3$ & $1 / 9$ \\
$\mathrm{~B}$ & 30 & 50 & & $1 / 3$ & $1 / 15$ \\
$\mathrm{C}$ & 50 & 30 & & $1 / 5$ & $1 / 15$ \\
$\mathrm{D}$ & 50 & 50 & & $1 / 5$ & $1 / 25$ \\
\hline
\end{tabular}

* The sprockets and chain are number 40 .

**With respect to the auger speed.

Table 4. Agitator speed in relation to the augur speed.

\begin{tabular}{|c|c|c|c|c|}
\hline \multicolumn{2}{|c|}{ Augur Speed } & \multirow[t]{2}{*}{ Combination } & \multicolumn{2}{|c|}{$\begin{array}{l}\text { Agitators Speed } \\
\text { (RPM) }\end{array}$} \\
\hline Dial & RPM & & Lower & Higher \\
\hline \multirow[t]{4}{*}{1} & 7 & $\bar{A}$ & 2.33 & 0.78 \\
\hline & & B & 2.33 & 0.47 \\
\hline & & $\mathrm{C}$ & 1.40 & 0.47 \\
\hline & & $\mathrm{D}$ & 1.40 & 0.28 \\
\hline \multirow[t]{4}{*}{4} & 24 & A & 8.00 & 2.67 \\
\hline & & B & 8.00 & 1.60 \\
\hline & & $\mathrm{C}$ & 4.80 & 1.60 \\
\hline & & $\mathrm{D}$ & 4.80 & 0.96 \\
\hline \multirow[t]{4}{*}{7} & 42 & $\bar{A}$ & 14.00 & 4.67 \\
\hline & & B & 14.00 & 2.80 \\
\hline & & $\mathrm{C}$ & 8.40 & 2.80 \\
\hline & & $\mathrm{D}$ & 8.40 & 1.68 \\
\hline \multirow[t]{4}{*}{10} & 54 & $\mathrm{~A}$ & 18.00 & 6.00 \\
\hline & & B & 18.00 & 3.60 \\
\hline & & $\mathrm{C}$ & 10.80 & 3.60 \\
\hline & & $\mathrm{D}$ & 10.80 & 2.16 \\
\hline
\end{tabular}

Once the four speed settings were repeated three times each, the sprockets and chains were rearranged to provide the next auger/agitators speed combination and the same testing protocol was followed until the four speed settings on the controller dial were tried. The testing of the rice husk and peat followed the same procedure except only the optimum sprocket combination and the proper auger and casing were used.

\section{RESULTS AND DISCUSSION}

\subsection{Physical Properties of Biomass}

The moisture content, bulk density and particle size of the two biomass materials were determined in this study. The moisture content varied from 9.08\% (rice husk) to $10.00 \%$ (wheat straw). The bulk density of the wheat straw (which had the higher moisture content) was $75.80 \mathrm{kh} / \mathrm{m} 3$ while the rice husk (which had the lower moisture content) had a bulk density of $92.00 \mathrm{~kg} / \mathrm{m} 3$.

AJeAS 
Table 5. Biomass weight and length distribution.

\begin{tabular}{|c|c|c|c|c|c|c|c|c|}
\hline \multicolumn{3}{|c|}{ Sieve } & \multicolumn{2}{|c|}{ Weight (\%) } & \multicolumn{4}{|c|}{ Length (mm) } \\
\hline \multicolumn{2}{|c|}{ Mesh } & \multirow[t]{2}{*}{ Opening } & \multirow{2}{*}{$\begin{array}{l}\text { Wheat } \\
\text { Straw }\end{array}$} & \multirow{2}{*}{$\begin{array}{l}\text { Rice } \\
\text { Husks }\end{array}$} & \multicolumn{2}{|c|}{ Wheat Straw } & \multicolumn{2}{|c|}{ Rice Husks } \\
\hline Number & Number & & & & Range & Average & Range & Average \\
\hline 1 & 7 & 2.8 & 2.90 & 2.06 & $30.0-59.0$ & 42.6 & $11.6-12.4$ & 12.0 \\
\hline 2 & 8 & 2.4 & 23.4 & 14.22 & $10.0-35.0$ & 22.5 & $10.2-11.4$ & 10.8 \\
\hline 3 & 10 & 2.0 & 35.0 & 23.60 & $3.0-19.0$ & 13.3 & $8.8-10.0$ & 9.4 \\
\hline 4 & 12 & 1.7 & 26.3 & 31.34 & $2.0-13.0$ & 9.0 & $6.2-8.0$ & 7.1 \\
\hline 5 & 14 & 1.4 & 7.60 & 18.72 & $1.1-5.0$ & 2.0 & $4.0-6.0$ & 5.0 \\
\hline 6 & 18 & 1.0 & 4.10 & 7.37 & $0.1-2.0$ & 0.5 & $3.2-4.0$ & 3.6 \\
\hline 7 & 20 & 0.9 & 0.00 & 1.17 & dust & dust & $1.5-2.4$ & 2.0 \\
\hline 8 & 25 & 0.7 & 0.00 & 0.67 & dust & dust & $0.8-1.2$ & 1.0 \\
\hline Pan & - & - & 0.80 & 0.85 & dust & dust & dust & dust \\
\hline
\end{tabular}

The width of the wheat straw ranged from $>0.1$ to $3.8 \mathrm{~mm}$

The width of the rice husk ranged from $>0.8$ to $3.4 \mathrm{~mm}$

The particles size distribution is shown in Table 5. The amount of dust (particle size $>1.0 \mathrm{~mm}$ ) in the wheat straw was $0.8 \%$ and $0.85 \%$ for rice husk. The average length varied from $>1.0$ to $42.6 \mathrm{~mm}$ for wheat straw and from $>1.0$ to $12.0 \mathrm{~mm}$ for rice husk. The width of wheat straw was $0.1-3.8 \mathrm{~mm}$ and $0.8-3.4 \mathrm{~mm}$ for rice husk.

The results showed that, both bulk density and particle size distribution had significant effects of the flowability and compactability of the biomass material in the hopper and auger casing as well as on the back flow of the hot gases, from the gasifier to the hopper. However, the variation in the moisture content was very small and this moisture content did not seem to have any effect (within the ranges) on the flowability of the material.

\subsection{Performance of Straw Feeding System}

Four auger speeds were used in the evaluation of the straw feeding system. These were 7, 24, 42 and $54 \mathrm{rpm}$, respectively. For each auger speed, four auger/agitators speed combinations were investigated. Three replicates were carried out for each combination and five straw bags were used for flow rate determinations. This resulted in 15 data points for each auger/agitators speed combination (or 60 data points for each auger speed). For each auger/agitators speed combination the mean, standard deviation and coefficient of variation were calculated as shown in Table 6.

The results indicated that the feeding system was capable of providing consistent straw output during each experimental run. However, both the auger speed and the agitators speed affected the straw output for a given sprockets combination.
Table 6. Straw output (kg/min).

\begin{tabular}{ccccc}
\hline $\begin{array}{c}\text { Augur } \\
\text { Speed } \\
(\mathrm{rpm})\end{array}$ & $\begin{array}{c}\text { Sprocket } \\
\text { Combination }\end{array}$ & \multicolumn{3}{c}{ Straw Output } \\
\cline { 3 - 5 } & & $\begin{array}{c}\text { Mean } \\
(\mathrm{kg} / \mathrm{min})\end{array}$ & $\begin{array}{c}\text { SD } \\
(\mathrm{kg} / \mathrm{min})\end{array}$ & $\begin{array}{c}\mathrm{CV} \\
(\%)\end{array}$ \\
\hline 7 & $\mathrm{~A}$ & 0.664 & 0.073 & 0.5 \\
& $\mathrm{~B}$ & 0.738 & 0.071 & 0.5 \\
& $\mathrm{C}$ & 0.660 & 0.019 & 0.1 \\
& $\mathrm{D}$ & 0.519 & 0.073 & 0.5 \\
\hline 24 & $\mathrm{~A}$ & 2.311 & 0.111 & 1.2 \\
& $\mathrm{~B}$ & 2.397 & 0.057 & 0.3 \\
& $\mathrm{C}$ & 2.368 & 0.144 & 2.1 \\
& $\mathrm{D}$ & 2.111 & 0.259 & 6.7 \\
\hline 42 & $\mathrm{~A}$ & 3.300 & 0.127 & 1.6 \\
& $\mathrm{~B}$ & 4.237 & 0.196 & 3.8 \\
& $\mathrm{C}$ & 4.220 & 0.212 & 4.5 \\
& $\mathrm{D}$ & 3.613 & 0.171 & 2.9 \\
\hline 54 & $\mathrm{~A}$ & 3.320 & 0.360 & 11.4 \\
& $\mathrm{~B}$ & 6.164 & 0.208 & 4.3 \\
& $\mathrm{C}$ & 5.749 & 0.273 & 7.5 \\
& $\mathrm{D}$ & 4.616 & 0.239 & 8.8 \\
\hline
\end{tabular}

$\mathrm{SD}=$ Standard Deviation

$\mathrm{CV}=$ Coefficient of Variation

Increasing the auger speed increased the straw feed rate. Also, for a given auger/agitators speed combination, increasing the upper agitator speed reduced the straw output. The results showed that the sprocket combination B produced the highest straw output at all augur speeds. The calibration curve for the straw feeder using this sprocket combination is shown in Figure 11.

The auger system and the reducer assembly were initially designed to feed chopped straw. This design allowed enough compaction of the chopped straw to stop the back flow of hot gases from the gasifier into the feeding system. 


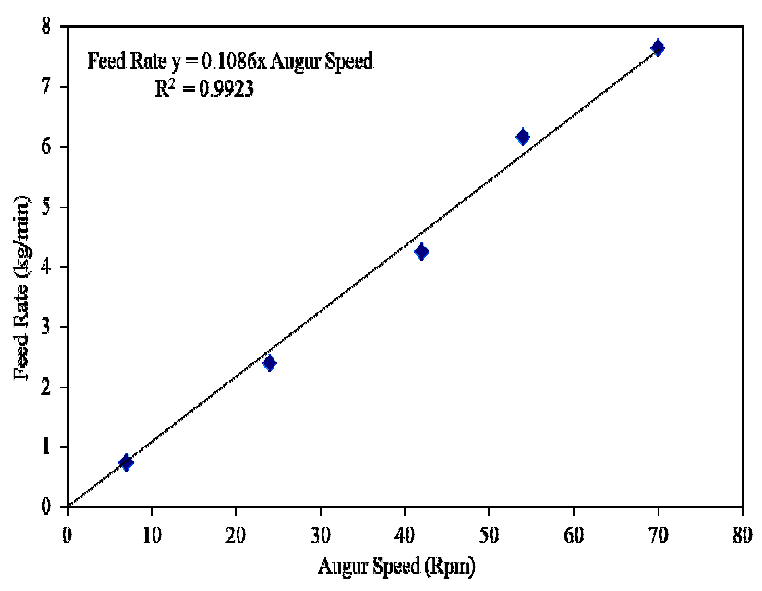

Fig 11. Calibration curve for the wheat straw feeder.

\subsection{Performance of Rice Husk Feeding System}

The auger system and the reducer assembly were modified to feed rice husk. The auger screw was maintained the same whereas the auger casing was modified. The design modification was necessary because the compaction of the rice husk using the initial feeding system designed for the chopped straw was not good enough to stop the backflow of hot gases from the gasifier into the feeding system. After comparing the compaction of rice husk and the chopped straw, the internal bore of the feeding system output was machined $4 \mathrm{~mm}$ larger to a final internal bore diameter of $64 \mathrm{~mm}$. The reducer assembly was made of $1.6 \mathrm{~mm}$ thick stainless steel, straight section of $100 \mathrm{~mm}$ in length and of $104 \mathrm{~mm}$ in diameter which was tig welded to a tapered section of $280 \mathrm{~mm}$ in length of $64 \mathrm{~mm}$ in diameter. A section of stainless steel sheet stock of 1.6 $\mathrm{mm}$ thick and $185 \mathrm{~mm}$ in length was welded around the tapered section to serve as a water-cooled zone. A stainless steel flange of $6 \mathrm{~mm}$ thick and $152 \mathrm{~mm}$ in diameter $(64 \mathrm{~mm}$ id) with two drilled holes of $9 \mathrm{~mm}$ in diameter was welded onto the output end of the reducer assembly. A second stainless steel flange of $6 \mathrm{~mm}$ thick and $152 \mathrm{~mm}$ in diameter (64 $\mathrm{mm}$ id) with six drilled holes of $9 \mathrm{~mm}$ in diameter was welded onto the input end of the reducer assembly. The calibration curve for the rice husk feeder is shown in Figure 12.

\section{CONCLUSIONS}

A feeding system for chopped straw and rice husk was designed, constructed and evaluated.

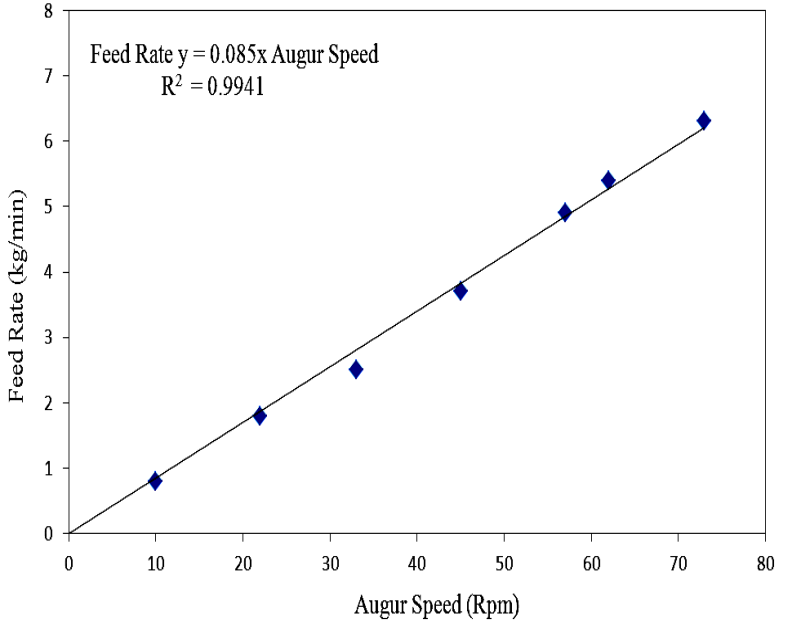

Fig 12. Calibration curve for rice husk feeder.

It consisted of: a frame, a hopper, an auger, two agitators, a drive system and a power unit. Initial testing showed that wheat straw and rice husk, being highly cohesive materials, created tunnel flow and piping conditions. This occurs when the pressure above an impending dome of material is too small resulting in the creation of a stable dome and blockage of the discharge. In order to achieve good flow conditions, it was concluded that the hopper must operate under "mass outflow" and the material should not be allowed to build up along the flow channels. These objectives were achieved by the proper redesign of the hopper configuration, the installation of agitators in the hopper and use of an auger in the outlet duct leading into the gasifier. However, as the augur was used to move the biomass material from hopper to the gasifier, it was observed that hot gases leaked from the gasifier into the hopper and heat was also transmitted from the gasifier to the hopper though the augur shaft resulting in burning of biomass material in the hopper. Therefore the augur shaft was fitted with copper tubing to serve as a water cooling system and the tapered section of the augur was fitted with a stainless steel section with water inlet and outlet to serve as a secondary cooling system. After, the system has been successfully modified for feeding wheat straw and rice husk, it was tested to determine the optimum operating conditions. Mass flow tests were performed with four sprocket combinations and four auger speeds. Increasing the auger speed and/or the lower agitator speed increased the straw output of the feeding system. 
However, increases in the upper agitator speed resulted in reduced mass flow of the material due to the mixing effect created by the upper agitator which reduced the down movement of the straw toward the auger housing. The sprocket B combination (30 tooth sprocket on the lower agitator shaft and a $\% 0$ tooth sprocket on the upper agitator shaft with a lower agitator speed of $1 / 3$ auger speed and an upper agitator speed of 1/15 auger speed) gave the greatest straw output. The feed rate at this combination ranged from 0.74 to $6.76 \mathrm{~kg} /$ minute $(12.58$ to $114.92 \mathrm{GJ} /$ minute). By adjusting the dial controller, the output could be easily matched with the gasifier's required straw input.

\section{ACKNOWLEDGEMENT}

The research was supported by the Natural Sciences and Engineering Research Council (NSERC) of Canada.

\section{REFERENCES}

Beagle, E. C., 1978. Rice husk conversion to energy. Food and Agricultural Organization of the United Nations, Rome, Italy.

Bridgewater, A. V., 1995. The technical and economic feasibility of biomass gasification for power generation. Fuel, 74(5), 631-653. DOI: 10.1016/0016-2361(95)00001-L.

Chum, H. L. and R. P. Overend, 2001. Biomass and renewable fuels. Fuel Processing Technology, 71, 187-195. DOI: 10.1016/S0378-3820(01)00146-1.

Demirbas, A., 2001. Biomass resource facilities and biomass conversion processing for fuels and chemicals. Energy Conversion and Management, 42, 1357-1378. DOI: 10.1016/S01968904(00)00137-0.

Demirbas, A., 2005. Potential applications of renewable energy sources, biomass combustion problems in boiler power systems and combustion related environmental issues. Progress in Energy and Combustion Science, 31, 171-192. DOI: 10.1016/j.pecs.2005.02.002.
Ebeling, J. M., and B. M. Jenkins, 1985. Physical and chemical properties of biomass fuels. Transactions of American Society for Agricultural Engineers, 28, 898-902.

FAO, 2013. Rice market monitor. Food and Agriculture Organization of the United Nations, XVI(1), 1-38, Rome, Italy.

IEA, 2012. Key world energy statistics. International Energy Agency.

Li, X., E. Mupondwa, S. Panigrahi, L. Tabil, S. Sokhansanj and M. Stumborg, 2012. A review of agricultural crop residue supply in Canada for cellulosic ethanol production. Renewable and Sustainable Energy Reviews, 16, 2954-2965. DOI: 10.1016/j.rser.2012.02.013.

Mansaray, K. G., and A. E. Ghaly, 1997. Physical and thermochemical properties of rice husk. Energy Sources, 19, 989-1004. DOI: 10.1080/00908319708908904

Olah, G. A., 2005. Beyond oil and gas: the methanol economy. Angewandte Chemie International Edition, 44, 2636-2639. DOI: 10.1002/anie.200462121.

Pushpakumara, B. H. J and G. H. M. J. S. De Silva, 2012. Characteristics of masonry blocks manufactured with rice husk ash (RHA) and lime. Engineer, XXXXV(3), 1-10.

Saxena, R. C., D. K. Adhikari, H. B. Goyal, 2009. Biomass-based energy fuel through biochemical routes: A review. Renewable and Sustainable Energy Reviews, 13, 167-178. DOI: 10.1016/j.rser.2007.07.011.

Shafiee, S and E. Topal, 2009. When will fossil fuel reserves be diminished? Energy Policy, 37, 181-189. DOI: 10.1016/j.enpol.2008.08.016.

Sims, R. E. H., H. H. Rogner and K. Gregory, 2003. Carbon emission and mitigation cost comparisons between fossil fuel, nuclear and renewable energy resources for electricity generation. Energy Policy, 31 , 1315-1326. DOI: $10.1016 /$ S03014215(02)00192-1. 